\section{¿Habrá suficiente atención de enfermería para los ancianos del futuro?}

El envejecimiento de la población, fenómeno demográfico observado en muchos países del mundo desarrollado y en desarrollo, obliga a los servicios de salud del mundo entero a asegurar un abastecimiento suficiente de personal de enfermería para cubrir las necesidades de la creciente población de ancianos. El problema se ve agravado por el carácter poco halagador de la profesión de enfermería en muchos países debido a la escasa remuneración del personal, a la mala situación que enfrentan las instituciones docentes, y a la poca participación del personal de enfermería en los procesos de decisión y planificación.

No necesariamente existe una relación directa entre el desarrollo socioeconómico de un país y el de la profesión de enfermería. En algunas sociedades pobres, el personal de enfermería es el encargado de casi todas las funciones administrativas del sistema de salud y de los servicios de atención primaria; en cambio, hay países ricos donde su ámbito de acción es mucho más reducido. No obstante, la disponibilidad de recursos económicos en una sociedad determinada sí afecta de una forma u otra al personal de enfermería, que en circunstancias muy difíciles emigra al extranjero o se traslada del campo a la ciudad en busca de mejores sueldos y oportunidades. Este éxodo de recursos humanos está mermando la profesión y constituye un grave problema para las instituciones sanitarias y educativas que quedan desprovistas de personal calificado.

En 1996 la Asamblea Mundial de la Salud adoptó por unanimidad una resolución a favor de dar mayor participación al personal de enfermería y a las parteras tradicionales en el proceso de reforma de los sectores de salud nacionales y en la determinación de las políticas sanitarias. Se trata de una medida dirigida a poder enfrentar, con la mirada puesta en el futuro, los problemas básicos de prestación de servicios que plantean no solo el envejecimiento de la población, sino el control de enfermedades infecciosas nuevas o reactivadas y las necesidades de la población maternoinfantil. Como componentes críticos e integrales de los sistemas de salud, el personal de enfermería y las parteras tradicionales pueden generar cambios extraordinarios en el estado actual de la atención y ser la única garantía de suficiencia de personal de salud en el futuro no muy lejano. (World Health Organization. WHO calls for strengthening nursing profession. Comunicado de prensa $\mathrm{WHO} / 7,24$ de mayo de 1996.)

\section{Necesidad de enseñar mecanismos para lidiar con el dolor moral}

Según una amplia variedad de fuentes, hoy en día el personal de los programas para personas adictas a las drogas intravenosas, especialmente en los centros urbanos, a menudo tiene que ver a sus pacientes padecer o morir de enfermedades crónicas como el sida sin saber lidiar con el dolor moral que esto despierta en los pacientes y sus familiares y, aun más importante, en ellos mismos. Si carecen de mecanismos que les ayuden a encarar y sobrellevar su propio malestar anímico, se tornan susceptibles al estrés y a un quebrantamiento por sobrecarga psíquica.

El sida ha tenido un efecto profundo en los programas de tratamiento de la drogadicción, siendo uno de ellos la necesidad de enseñar a los asesores de pacientes a manejar el intenso dolor moral que acompaña a esta dolencia. De marzo a mayo de 1995, la Administración del Abuso de Sustancias y de Servicios de Salud Mental de los Estados Unidos de América patrocinó una encuesta telefónica de 42 centros de tratamiento en las ciudades de Nueva York, San Francisco y Chicago. Se enfocaron cuatro aspectos en particular: 1) la incidencia de infección por virus de la inmunodeficiencia humana (VIH) y sida entre la clientela y los miembros del personal; 2) la incidencia de muertes por sida en estos dos grupos, 3) la opinión del personal en torno a la importancia de la capacitación sobre el manejo del dolor moral, y 4) la medida en que los profesionales habían recibido este tipo de capacitación.

Los resultados revelaron una incidencia de infección por VIH y sida de 7 y $2 \%$, respectivamente, en clientes de los centros de Chicago; de 20 y $6 \%$ en los de San Francisco; y de 24 y 13\% en los de Nueva York. La muerte de clientes con sida fue común en casi todos los centros encuestados. En cuanto a la presencia de infección por VIH o sida en miembros del personal, seis programas en San Francisco, cuatro en Nueva York y tres en Chicago declararon que sí había trabajadores infectados, aunque no dieron cifras específicas. 
De los 38 centros que poseían información sobre el ofrecimiento de capacitación para el manejo del dolor moral, 26 afirmaron haberla ofrecido en algún momento y 18 de estos en los últimos 12 meses. La encuesta reveló la importancia que se concede a este tipo de capacitación, tanto para la clientela como para miembros del personal. En una escala de aprobación de 4,0 puntos, la capacitación del personal recibió un promedio de 3,8 puntos, y la de la clientela, de 3,6. Los aspectos de la capacitación en que más énfasis pusieron los trabajadores de los centros fueron los siguientes: 1) el respeto a la dignidad humana de personas con infección por VIH o sida; 2) la ayuda emocional de enfermos desmoralizados y decaídos; 3) el manejo del estrés y del quebrantamiento mental; 4) el enfrentamiento de sus propios sentimientos de pérdida, y 5) la actitud frente a la muerte y al proceso de morir. (Substance Abuse and Mental Health Services Administration. Survey of counselors finds need for grief training. SAMHSA News 1996;summer:13-14.)

\section{Manejo de las infecciones respiratorias agudas infantiles en Pakistán}

En Pakistán, las infecciones respiratorias agudas (IRA) causan más de una cuarta parte de todas las defunciones de niños menores de 5 años en el seno de la comunidad y un tercio de las que ocurren en hospitales. Diferentes factores, tales como la búsqueda inoportuna de atención médica, el diagnóstico atrasado o equivocado y el uso inapropiado de antibióticos, suelen ser los responsables de la aparición de complicaciones y de la alta mortalidad. En 1989 el gobierno de Pakistán lanzó el Programa Nacional para el Control de las IRA con el fin de reducir la mortalidad por neumonía en menores de 5 años y racionalizar el uso de medicamentos. En el contexto de esta iniciativa, las medidas estandarizadas recomendadas por la OMS para el tratamiento de casos de IRA se instituyeron y adaptaron a las necesidades locales y, desde principios de 1990, han sido parte del adiestramiento de los miembros del equipo médico del hospital de Islamabad.

Un grupo de investigadores estudió los registros de pacientes ambulatorios y hospitalizados que fueron atendidos en el hospital de Islamabad de 1989 a 1992 para determinar si el programa establecido por el gobierno de Pakistán había producido beneficios palpables. El análisis reveló que durante ese período el uso de antibióticos en el servicio ambulatorio se redujo de 54,6 a $22,9 \%(P<0,0001)$ y que la tasa de letalidad en niños ingresados por IRA bajó de 9,9 a $4,9 \%(P=0,0001)$, mientras que la tasa de letalidad en niños con IRA en general se redujo de
8,7 a $6,2 \%$. Estos resultados, que se basan en datos procedentes de un centro de atención terciaria, confirman la eficacia del manejo estandarizado de los casos de IRA recomendado por la OMS, con el que se redujo el uso de antibióticos y el gasto en medicamentos por un lado, y la mortalidad por IRA por el otro. Los criterios de la OMS para el ingreso de pacientes son más sensibles que los criterios convencionales de radiología y auscultación y por lo tanto llevan a un mayor número de ingresos. No obstante, los beneficios observados en términos de la menor mortalidad por IRA justifican plenamente su adopción y deben servir de estímulo a los países de la Región. (Quazi SA, et al. Standard management of acute respiratory infections in a children's hospital in Pakistan: impact on antibiotic use and case fatality. Bull World Health Organ 1996;74:501-507.)

\section{El matrimonio: ¿medida sensata para la buena salud?}

Es un hecho bien documentado en numerosos estudios que los adultos casados gozan de mejor salud general y tienen menos morbilidad y mortalidad que los solteros. Para explicarlo se han propuesto dos hipótesis. Según la primera, la salud se beneficia del apoyo moral y económico conferido por el matrimonio. De acuerdo a la segunda hipótesis, las personas sanas ya de por sí son más propensas a casarse y posiblemente a permanecer casadas. Por otra parte, las personas enfermas no son tan apetecidas como compañeras de vida y su estado de salud puede, además, causar tensiones dentro del matrimonio que aumentan las probabilidades de un divorcio. Ambas hipótesis se pusieron a prueba en un estudio prospectivo basado en una encuesta nacional de mujeres que tenían de 24 a 34 años de edad al comienzo de dos períodos consecutivos de 5 años.

Los resultados del estudio revelaron un efecto patente de tipo protector, pero solo entre mujeres sin empleo. En este grupo, las casadas gozaron de mejor salud que las solteras durante ambos períodos de seguimiento. El análisis prospectivo de los datos también demostró un ligero efecto de selectividad. Es decir, las mujeres que desde un principio estaban en mejores condiciones de salud mostraron una mayor disposición a casarse y se divorciaron con menos frecuencia, pero solamente cuando no tenían un empleo de jornada completa y solo en el primer período de seguimiento.

En general, estos datos sugieren que el marcado efecto beneficioso que tuvo el matrimonio en mujeres sin trabajo se debió tanto a un fenómeno de protección como al efecto de la selectividad. Ninguno de los dos se documentó en mujeres que tra- 
bajaban a tiempo completo. Las mujeres solteras y sin empleo mostraron un estado de salud mucho más precario que todas las demás y a ello se sumaban otras desventajas, como la estrechez económica y la presencia de rasgos sociodemográficos que contribuían a la dificultad para conseguir empleo. (Waldron I, et al. Marriage protection and marriage selection-prospective evidence for reciprocal effects of marital status and health. Soc Sci Med 1996;43:113-123.)

\section{Factores que protegen contra las conductas delictivas}

Un estudio financiado por el Instituto Nacional del Abuso de Drogas, de los Estados Unidos de América, ha identificado una serie de factores cuyo efecto acumulativo puede ayudar a jóvenes en situaciones de riesgo a no caer en la drogadicción y la delincuencia. Según este estudio, la presencia de estos factores en distintas facetas de la vida de un adolescente - la familia, la escuela, los amigos, el vecindario, y demás- contribuye de manera decisiva a la resistencia a ambas conductas. Este descubrimiento abre el camino para la adopción de nuevas intervenciones preventivas.

No todos los niños expuestos a factores de riesgo conocidos se entregan a los narcóticos o a la delincuencia cuando llegan a la pubertad. El estudio efectuado consistió en el seguimiento desde 1988 de una muestra de 1000 adolescentes de ambos sexos provenientes de hogares conflictivos en la zona urbana de Rochester, Nueva York. Los factores de riesgo examinados fueron, entre otros, el desempleo del principal proveedor de la familia, la presencia de antecedentes familiares de abuso de drogas o de delincuencia, o el haber sufrido maltrato o abuso sexual antes de los 12 años de edad. A los jóvenes que habían estado expuestos a un mínimo de cinco factores de este tipo se les consideró en muy alto riesgo de volverse drogadictos o delincuentes.

Aunque al cabo de solo 12 a 18 meses después de iniciado el estudio estos jóvenes en mayor peligro mostraron una tendencia mucho más marcada a usar drogas y a tener conductas delictivas que los que tenían cuatro factores de riesgo o menos, durante ese período $60 \%$ de los adolescentes en mayor riesgo no habían iniciado ninguno de estos comportamientos. Los factores que casi invariablemente marcaron la distinción entre los dos grupos de adolescentes fueron los siguientes: 1) factores familiares: la supervisión cercana de los padres y una relación de mutuo afecto entre estos y el niño; 2) factores educacionales: la aptitud del niño para las matemáticas y las funciones verbales, su dedicación a las actividades académicas y su apego a los maestros; el deseo de los padres de ver al niño asistir a la universidad y el valor que asignan a los estudios universitarios, y 3) factores sociales: la presencia de amiguitos con valores convencionales y la actitud aprobatoria de los padres hacia las amistades del niño. Cabe resaltar que la acumulación de factores protectores en todas estas áreas es la responsable del efecto beneficioso observado, y no cada factor en lo individual. El reto para la salud pública consiste en encontrar maneras de introducir estos factores protectores en la vida de adolescentes que se crían en hogares subprivilegiados. (Mathias R. Protective factors can buffer high-risk youths from drug use. NIDA notes 1996;11:7-9.)

\section{Efecto letal de la tuberculosis en pacientes de sida}

Más personas con infección por virus de la inmunodeficiencia humana (VIH) mueren de tuberculosis que de cualquier otra causa. Si se mejorara el tratamiento de esta enfermedad, los pacientes infectados por VIH cobrarían un promedio de 2 años de vida adicionales y dejarían de ser una fuente de contagio para sus parientes y amistades. "Un mundo, una esperanza", lema del Día Mundial del Sida celebrado el 1 de diciembre de 1996, refleja el tema central de la 11a Conferencia Internacional sobre el Sida que tuvo lugar en Vancouver, Columbia Británica, en julio de 1996. En dicha ocasión el director ejecutivo del Programa Conjunto de las Naciones Unidas sobre el Sida (ONUSIDA) afirmó que el descubrimiento de mejores tratamientos y regímenes multimedicamentosos son nueva fuente de esperanza para personas con VIH cuya situación económica les permite adquirirlos. Por primera vez desde que comenzó la epidemia de infección por VIH y sida hace 15 años, se vislumbra la posibilidad de disminuir la propagación de estas afecciones y aliviar el sufrimiento que ocasionan. Esto no implica, sin embargo, que el sida esté próximo a desaparecer. Diariamente se infectan alrededor de 8500 nuevos individuos, de lo cuales 1000 son niños menores de 15 años, y más de 22 millones de personas en el mundo ya están infectadas. La proporción de casos en mujeres ha aumentado y actualmente representa $42 \%$ del total. En general, casi 8 millones de personas, entre ellas 1,5 millones de niños menores de 15 años, ya han contraído el sida desde que empezó la epidemia y alrededor de 6 millones de ellos han fallecido. Lamentablemente, en algunos países la epidemia apenas empieza y en otros está completamente fuera de control. Pero en medio de todo este 
panorama tan sombrío, hay lugares donde se ha obligado a los VIH a ponerse en alerta.

Algunos medicamentos anti-VIH, usados solos o en combinación, han logrado atrasar la progresión del sida y reducir la carga vírica en pacientes ya infectados. Uno de ellos, la zidovudina (AZT), reduce las probabilidades de transmisión de madres infectadas a sus recién nacidos, pero en general cualquier avance tecnológico es costoso y beneficia principalmente a personas pudientes en países desarrollados. Más asequibles y promisorias son las intervenciones educativas, cuyos beneficios se han documentado no solo en sociedades avanzadas sino también en países pobres. Con el respaldo de un fuerte compromiso gubernamental y de programas como el ONUSIDA, las estrategias preventivas pueden producir efectos extraordinarios. Para ganar la batalla contra los $\mathrm{VIH}$, se requieren, sin embargo, una mayor solidaridad entre personas infectadas y no infectadas, así como la participación de organizaciones femeninas, grupos juveniles, las fuerzas armadas, la población de enfermos y las personas en riesgo de infectarse en virtud de su ocupación o estilo de vida. (Joint United Nations Programme on HIV/AIDS. World AIDS Day 1996: One world. One hope. Materiales de información pública, 1996. Se puede solicitar información a: UNAIDS, 20 Avenue Appia, Genève, Suiza.)

\section{Necesidad urgente de planificación familiar en países en desarrollo}

En el mundo en desarrollo, más de 100 millones de mujeres casadas (una quinta parte del total) desean prevenir el embarazo pero no usan métodos anticonceptivos, bien sea por temor a sus efectos secundarios, falta de acceso a información o a servicios de calidad, o la desaprobación del cónyuge. Según un estudio efectuado por el Programa de Información Poblacional de la Universidad de Johns Hopkins, en Baltimore, Estados Unidos de América, se necesitan estrategias que presten atención específica a estos problemas a fin de cubrir las necesidades aún no satisfechas de millones de mujeres que desean planificar su familia. En términos absolutos, la India tiene el mayor número de mujeres (cerca de 30 millones) en esta situación. Le siguen otros países del Asia, con un total de 32 millones, así como del África, con 22; de América Latina, con 11; y del Cercano Oriente y el Norte de África, con 6. Entre los países con un gran número o porcentaje de mujeres cuyas necesidades en el campo reproductivo no están satisfechas figuran Bangladesh, Egipto, Indonesia, México, Nigeria, Pakistán y Vietnam.
Estas conclusiones se basan en los resultados de encuestas a gran escala y en estudios efectuados en distintos países sobre las preferencias y prácticas reproductivas de la población femenina. Aunque existe poca información sobre las preferencias reproductivas de mujeres solteras, el elevado número de abortos practicados anualmente en el mundo en desarrollo es un indicador adicional de la urgente necesidad de poner los anticonceptivos al alcance de todas las mujeres. Para poder establecer buenos programas de planificación familiar, hay que empezar por saber qué factores obstaculizan el acceso a los anticonceptivos, qué puede hacerse al respecto y qué medidas se pueden adoptar para mejorar y ampliar las redes de comunicación y de servicios destinadas a la población femenina. Es fundamental adoptar una estrategia a base de cuatro elementos: 1) mejores servicios de planificación familiar y mayor acceso a los anticonceptivos; 2) asesoramiento individual y uso de los medios de comunicación pública; 3) uso de anticonceptivos por el hombre y no solo por la mujer y participación del hombre en la planificación de la familia; y 4) vínculos más fuertes con otros servicios de salud maternoinfantiles. (The Johns Hopkins University. Hopkins report: millions of women need family planning in the developing world. Comunicado de prensa, 15 de noviembre de 1996.)

\section{Carta en pro de los derechos sexuales y reproductivos}

En la Asamblea de Miembros de la Federación Internacional de Planificación de la Familia (IPPF) que se celebró en noviembre de 1995 en Manila, Filipinas, se adoptó una nueva Carta de Derechos Sexuales y Reproductivos a fin de dar mayor definición a la labor de la Federación en las décadas venideras. La Carta es una defensa firme y elocuente de la libertad de todos los seres humanos en el campo de la sexualidad, independientemente del contexto político, económico o cultural en que se desenvuelvan. Doce derechos fundamentales fueron claramente enumerados en la Carta. El primero, que es el derecho a la vida, comprende la prerrogativa de una mujer de no colocar su vida en riesgo por razones de procreación. Le sigue el derecho a la libertad y a la seguridad personales, aun en el ámbito de la vida sexual y reproductiva, que lleva implícita la noción de que ninguna mujer debe ser sujeta al embarazo, a la esterilización o al aborto contra su voluntad.

En la Carta se reconoce el derecho a la igualdad y a estar libre de toda forma de discriminación, particularmente en el campo de la sexualidad. También se proclaman los derechos a la vida privada, a 
la libertad de pensamiento, a la información y educación, a elegir el estado civil y a decidir el número de hijos y el momento adecuado para tenerlos, aun dentro del matrimonio. Por último, la Carta defiende el derecho a la atención y protección de la salud; a cosechar los frutos del progreso científico, especialmente en términos del acceso a tecnologías reproductivas modernas, seguras y aceptables; a la libertad de reunión y a la participación política, y a no sufrir torturas ni tratos denigrantes. Esto incluye el derecho de los niños a ser protegidos de la explotación y del abuso sexual.
El contenido de la Carta se inspira en otros instrumentos de ética y derechos humanos reconocidos mundialmente. Aunque garantizar estos derechos constituye un desafío para todos los países, la adopción de la Carta como instrumento fundamental en el campo de las políticas reproductivas augura cambios de actitud y práctica fundamentales sin los cuales se dificulta todo progreso en el área de la planificación familiar. (Carta de IPPF de Derechos Sexuales y Reproductivos. En: Federación Internacional de Planificación de la Familia. Informe Anual 1995-1996. IPPF; 1996:6.)

\begin{tabular}{c} 
Premio Abraham Horwitz en Salud Interamericana, 1997 \\
Fecha límite: 31 de marzo de 1997 \\
La Fundación Panamericana de la Salud y Educación (PAHEF) acepta nominaciones para \\
el vigésimo Premio Abraham Horwitz en Salud Interamericana. El premio se financia mediante \\
un fondo constituido por aportaciones de amigos del Dr. Abraham Horwitz, Director Emérito de \\
la OPS, y se creó con objeto de reconocer su notable contribución a la salud de las Américas. \\
El premio consiste en un diploma y US\$ 1000, y persigue el objetivo de estimular la \\
excelencia y el liderazgo en salud entre las personas que trabajan en las Américas y generan \\
ideas y trabajo de interés primordial para la Región. El Comité del Premio recomendará un can- \\
didato a la Junta Directiva para su aprobación final, y el premio se entregará en la reunión del \\
Consejo Directivo, que se celebrará en septiembre de 1997. \\
Las autoridades de salud de los países miembros, el personal de la Organización y otras \\
personas interesadas en el trabajo de la OPS y la PAHEF quedan invitados a presentar nomina- \\
ciones de personas o grupos de personas que hayan hecho aportaciones científicas o pedagó- \\
gicas notables en el campo de la salud interamericana. El Comité del Premio considerará todas \\
aquellas nominaciones que incluyan la siguiente información: nombre, dirección y posición \\
actuales de la persona nominada; descripción detallada de los logros espećficos que haya \\
alcanzado y se juzguen merecedores de dicho premio, especificando su relevancia para la \\
Región de las Américas; currículum vitae completo y una breve nota en la que se resuman los \\
motivos por los que se considera que la persona nominada debe recibir el premio. \\
Las nominaciones han de recibirse antes del 31 de marzo de 1997 y deben dirigirse a: \\
Chairman \\
PAbraham Horwitz Award Committee \\
PAHEF \\
525 Twenty-third Street, N.W. \\
Washington, DC 20037 \\
Estados Unidos de América \\
\hline
\end{tabular}

